\title{
Embedding a physical health nurse consultant within mental health services: consumers perspectives
}

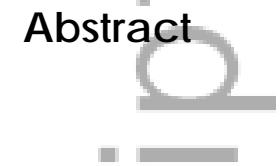

The life expectancy of people living with mental illness is signific a ntly shorter than that of the rest of the population. Despite the profound impact of physical health issues on both quality of life and life expectancy, the perspectives of mental health consumers have yet to be thoroughly explored. Furthermore, research has foc used far more on desc ribing ba miers than on identifying solutions. This pa per reports on find ings from a qualitative exploratory research study with the a im to examine the potential role of a specialist nurse with advanced physic al health care skills. Foc us groups were conducted with 31 consumers. Data were analysed thematic ally. The concept of a role like this was supported; however, partic ipants stressed: i) the importance of integration between health professionals and various components of the health care system, and, ii) the need for culture change for nurses to work from a less medic ally-dominated approach. Previous research litera ture suggests a nursing position dedic ated to physic al health care and coord ination may produce positive outcomes for mental health

This is the author manuscript accepted for publication and has undergone full peer review but has not been through the copyediting, typesetting, pagination and proofreading process, which may lead to differences between this version and the Version of Record. Please cite this article as doi: 10.1111/inm.12185

This article is protected by copyright. All rights reserved. 
consumers. Find ings from the current research project emphasise the need for consumers to be identified as key stakeholders in a solution-focused approach to improved physical health care for mental health consumers.

\section{Keywords}

Physical health

Mental illness

Specialist nurse role

Integration

Culture change

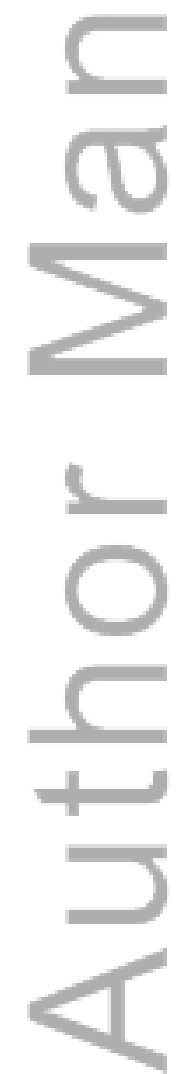




\section{Introduction}

Preventable physical illnesses are of higher prevalence among mental health consumers. Illnesses, partic ula rly cardiova sc ular disea se and diabetes, account for the drastic ally reduced life expectancy for people with mental illnessand contribute to poorgeneral health and reduced life expectancy (Lawrence et al. 2013; National Mental Health Commission 2014), Riskbeha viours for cardiova sc ular disea se and other chronic physical illnesses are higheramong people with mental illness. These include high levels of smoking, low levels of physic al a c tivity, and poor diet (Mitc hell et al. 2015; Stanley \& La ugha me 2014). At the outset these lifestyle factors, coupled with the adverse impact of medications, and amplified by social and economic marginalisation, contribute to the elevated prevalence of physical illnesses among consumers (Robson \& Gray 2007). To provide an equitable standard of care to this vulnerable population, formidable systemic issues must be resolved (Robson \& Gray 2007).

Consumer-specific health care services designed to prevent, manage and treat physical illnesses were consistently found to be either less accessible or of lesser quality than ma instream altematives (Lambert \& 
Newcomer 2009; Lawrence \& Kisely 2010). Despite these findings, research examining attitudes to the quality and a vaila bility of physic al health services for mental health consumers has been confined almost exc lusively to seeking the opinions of health professionals (Robson et al. 2013; Hyland et al. 2003; Wheeler et al. 2010). Minimal attention has been paid to the consumers who have accessed or seek to access physic al health services (C had wick et al. 2012). A comprehensive exa mination of the views of consumers regarding access and experience of physical health care is needed to guide the translation of consumer participation from a polic y metoric into qua lity servic delivery (Commonwealth of Australia 2013).

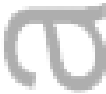

More recently we have observed a growth in health care strategies of improving physical health, such as lifestyle and education programs, changing medication approaches, integrating wide-ranging services within a single locale, and enhanced physic al screening and referral systems (McKenna et al. 2014; Millar et al. 2014; Lorig et al. 2014). Despite such growth, input has rarely been sought from consumers of mental health servic es about what physical health services are needed and how such services might operate (Commonwealth of Australia 2013). Where consumers have been involved their role has tended to be relatively passive, 
for example responding to surveys developed by health professionals or academics to changes in behaviour and attitude, or consumer satisfaction (Brunero \& Lamont 2010; Shuel et al. 2010; Bradford et al. 2008; Brunero et al. 2008). Consumer involvement in research which actively seeks their views and opinions a bout initia tives to improve physical health is therefore vital. It is also apparent that the policy platform for mental health consumer participation within the recovery paradigm has largely excluded any reference to physic al well-being.

In the rare instances that the consumer perspective about physical health has been included, the find ings have been insightful, outlining the challenges for all parties and corresponding practical solutions (Sc hmutte et al. 2009; Cha dwick et al. 2012). For example, an integra tive review of ba miers to physical health services by Happell, Scott and Platania-Phung (2012b) noted numerous ba miers in the process of health care interaction for mental health consumers including disc onnection from required physic al health care services, and a sense of interpersonal neglect upon a mival at a primary health care service. The voic ing of physical health problems was not taken seriously during consultations, and the uptake of any referrals was low. 
Discrimination and professional siloing were central to these perceptions of disconnection to physical health care.

The creation of a physic al health nurse consultant (PHNC) position is proposed here as an effective strategy to mitigate these issues to improve the monitoring and management of cardiometabolic risks (Brunero \& Lamont 2009). These positions, generally referred to as Cardiometabolic Health Nurses $(\mathrm{CHN})$, are specia list nursing positions, specific ally designed to improve physical health services in mental health settings (Mc Kenna et al. 2014; Nankivell et al. 2013; Happell et al. 2014b). Embedding this position within public mental health service provision is congruent with holistic and recovery-orientated care. Formative studies have found that nurses in mental health care have been receptive to this type of role (Happell et al. 2012a; Happell et al. 2014a).

\section{(2)}

Services provided by the PHNC would include screening, facilitation of referrals, and facilitating continuity of comprehensive physic al health care, thus adopting a collaborative approach to care (Happell et al. 2012a). Preliminary eva lua tions cautiously suggest the introduction of such a nursing role may contribute to improved physical health care outcomes among 
consumers. (Happell et al. 2012a; Happell et al. 2014a). It is however crucial that further research incorporates consumer perspectives on the development of a PHNC role and this proposed method of physical health care service delivery.

In a recent survey undertaken by the Australian Capital Temitory, Mental Health Consumers Network (ACTMHCN) to identify the major prio rities for consumers in the Australian Capital Temitory (ACT), physic al health was ranked third in importance. In acknowledgement of the magnitude of physical health needs for consumers of mental health servic es, and the absence of consumers' voices in both identifying the problem and seeking solutions. The current study explores one component of this broader agenda to seek the views and opinions of consumers regarding the introduction and implementation of a physic al health care nursing position within the mental health clinic al team.

\section{Methods}

Design 
A qua litative exploratory design was utilised based on the work of Stebbens (2001). Qualita tive exploratory research enables the deta iled exploration of a topic or issue from the perspective of a particulargroup of participants. It is an effec tive approach to examining areas of importance that have not been well researched to date, and broadening the understanding of the issue by including partic ipants who are traditionally marginalised in formal decision making processes.

Setting and rec ruitment

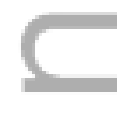

The research was undertaken in the ACTwith the full support of ACTMHCN, the ACT consumer peak body which represents the interests of consumerperspective polic y development and other formal decision-ma king forums. ACTMHCN advertised the project in their weekly bulletin for members. Participant Information and consent forms were provided on request. Prospective participants were invited to select from four dates and times for foc us groups. ACTMHCN kept registration data confidential. A total of 31 adult consumers participated in the focus groups, ranging from seven to nine pergroup. Consumers were paid for their time as per rate and policy of the ACTMHCN. 
Procedure

The ACTMHCN was selected as an ideal venue for its central loc ation, its familianity to many of the partic ipants, accessibility to public transport and to emphasise the organisation's support for this research. Foc us groups were conducted by a mental health nursing researcher and a consumer researcher, both with signific ant expertise in the conduct of focus groups and working with mental health consumers. The researchers had extensive knowledge of the physical health needs and concems of consumers of mental health services; ga mered from academic, advocacy and lived expenience perspectives. The researchers briefly described themselves and their professional or personal experience at the commencement of each interview. The inclusion of a consumer researcher is congruent with the spint of co-produced research and also encouraged more frank disclosure than might have otherwise occured.

An interview guide was prepared by the researchers. The questions were intentionally broad to allow scope for participants to describe their experiences and opinions without restric tions. Partic ipants were provided a 
brief desc ription of the role of the proposed specialist physic al health ca re nurse and asked to consider whether such a role might be valuable in improving physical health care, and if so in what way. The findings from this question and broader disc ussion about the role of nurses in addressing physic al health issues are presented here. Duration of focus groups ranged between 90 and 150 minutes. The groups were audio recorded to provide an accurate record of the interviews.

Ethic al issues

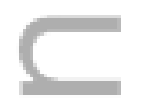

Ethical a pproval for the study was obta ined from the University Ethics Committees representing the research tea $\mathrm{m}$. Partic ipants were required to sub mit a signed consent form prior to commencement of the interview. A brief outline of the study (as described in the plain language statement) was provided verbally at the beginning of the interview and participants were encouraged to a sk questions or seek cla rific ation. Partic ipants were assured that their privacy and confidentia lity would be mainta ined and no names of people or health servic es would be published. The researchers explained that recording was solely to ensure an accurate interview transcript and all partic ipants ind ic a ted their approval for interviews to be taped. All 
partic ipants were also a sked to respect confidentia lity of others by not disclosing any information disclosed in the focus group.

Data a nalysis

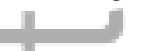

Each interview was transc ribed verbatim by an extemal transc ribing service to provide an accurate account of the interviews. Data analysis was undertaken independently by two members of the research team. Thematic analysis was conducted based on the framework developed by Braun and Clarke (2006), frequently used as a qualitative data analysis tool. This approach involves reading transcripts numerous times to enhance appreciation of the data and the voice of participants. The next step involves identifying and manually coding specific areas of content. The codes were then reviewed and clustered according to similar features. Tentative themes were identified and provisionally labelled. A conceptual map was constructed of the tentative themes and they were rechecked for accuracy and to determine if all key information was extracted from the data. The tea $m$ reviewed the thematic structure and modific ations were made until a consensus was able to be achieved. The research focus and primary aim was to ascerta in consumer perspec tives on the value of a specialist physic al health nursing role within mental health care provision. Two sub-themes were 
identified: the importance of integration, and the need for a culture shift. These sub-themes are explored below and supported with direct quotes from foc us group partic ipants.

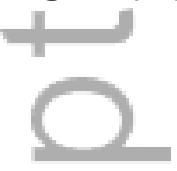

\section{RNDINGS}

Importance of integration

The responses to the concept of a specia list nursing position in mental health were largely positive. It a ppears this potential stra tegy has merit as a means of a ddressing the consumer-identified complex physic al health problems, issues and ba miers to care. The extract below demonstrates some of the ways that partic ipants desc ribed their current physical health care and trea tment as inadequate. There is potential c apacity for this new nursing role to facilitate the integration of physic al health care into mental health services.

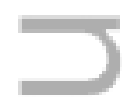

Often mental health nurses and doctors will overlook all or not be able to treat medical complaints, which can escalate and play on your 
mind if you're not feeling well and the more unwell you become the more it hurts. And sometimes mental health people don't see the medical aspect side of it and they don't link them together. So it's often hard to be treated for medical health problems by mental health staff ... (1)

As in the following extract, a specialist nursing role was seen as partic ulanly a ppealing in traversing professional silos and at least providing baseline cardiometabolic data for practitioners.

I'd like to see a service at the hospital that just specialises in medical health of mental health patients, so that you can identify things that are making their life hard or things that they could be complaining and what are they depressed about, because they're in actual physical pain most of the time (2).

Furthemore, partic ipants sa w benefits in facilitating the integration of services they already accessed and an inc rea sed emphasis on holistic care within mental health services, including health education: 
There needs to be people trained in both mental health and physical that know about food and nutrition and vitamins and minerals and how they all play a part and can interact ... (1)

Integration was also very important in facilitating closer communic ation between health professionals. A fundamental lack of communic ation could otherwise pose a signific ant ba mier to the effectiveness of this initia tive:

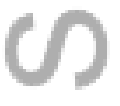

.... it would be a nice go-between for the person to make sure that everybody is talking together but there needs to be a massive shift first because doctors don't want to share. Nurses don't want to share, social workers don't want to share, psychia trists don't want to share. (3).

Without first addressing the integration problem there wasconcem that an additional position might further exacerbate rather than overcome the problem:

you don't want them to be just another rung in the ladder either ... you'd see your doctor, then your doctor goes, "Oh, you can see the 
nurse, she'll do your physical health." So then you'd have to see the nurse and then depending on what the nurse says, you know ... having another person in that (3).

Participants raised the ongoing problem of having to repeat their history numerous times and were frequently a nswer similar questions a sked by va rious health professionals. The specialist nursing position had potential to assist with addressing physic al health issues but a coord inated approach was important to avoid repetition:

It would be a good portal, where you've ... had your chat with your doctor ... in terms of mental health, as you move across to the nurse that's looking into the physical health and wellbeing. But you don't need to go over your story a ga in (1).

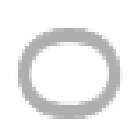

Need for a culture shift

Although the potential of the specialist nursing role was widely supported, some participants had a very clear view that these roles were more suited to the community rather than the inpatient setting to change the 
focus from the more clinical aspects of $c$ are to those that would enhance health and wellbeing at a more psychosocial level:

. we need more nurses... out in the community, on the ground where people are struggling to live independently in their homes or trying to get those links ... to the healthy activities ... the psychosocial stuff that with diet, nutrition, sleep ... I think it's great the more the mental health nurses get into that, but it's really a community psychosocial model rather than a clinic al model (4)

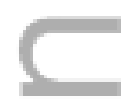

The importance of this type of resource in the community was identified by many as a necessity given the relative lack of resources available and the capacity for specialist nurses to address physical health care needs in that environment:

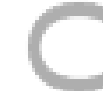

- - people were thrown into the community, and the resources didn't follow. There have been improvements since the Inquiries, seeing mental health consumers living in poverty in boarding houses and being exploited ... But there's still not enough - from this disc ussion - still a lot more needs to be done in the community ... (2) 
Although there was a divergence of opinion on this point, the view was expressed that transitioning to this type of role may not come easily to many nurses, due to the way they have been educated and socialised into a biomedic al approach.

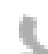

2

there's a real political and social and stigma resistance to allowing that sort of freedom within the clinic al professions to have that mobility and flexibility and getting out of their clinics or in their hospitals - - it's politically systemic in the way that nurses and doctors are trained to perform and the way they're funded, all reinforces a model that locks them into a certain way of relating to people (4).

The power embedded in health professionals as a result of their expertise was seen as a major bamier to nurses working outside what participants regarded as their usual scope of practice, with a reluctance to give up power to engage with consumers in a way that reflects recoveryoriented practice, psychosocial and health promotion principles: 
... that's the shift that the clinicians don't want to really make, they're the top dogs, this is our authority, this is our turf, this is what we do (4).

The need for consumers to be actively engaged in the development of roles such as these was clearly stated. At the minimal level there was an expressed need for an advisory group that included consumer representation to provide formal input:

(s)

if mental health nurses are going to have a committee to help how we develop these sorts of new approaches, then please get a consumer advocate rep on there that can bring that exactly those critic al skills of lived experience (4).

\section{Disc ussion}

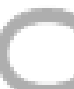

The find ings in the current study suggest a specia list physic al health nurse consultant may play an important role in addressing the physical health inequities faced by consumers of mental health servic es, albeit with some logisticalconcems. To date the literature has been effective in identifying the physical health issues experienced (Happell et al. 2015; Kaufman et al. 
2012; Millar et al. 2014). However, it is now time to move from the identific ation of the problem to finding solutions and address this long standing inequity in access to, and the provision of, physical health care. The find ings of the current study are signific ant in facilitating dia logue between consumers and health professionals by seeking and artic ulating the views and opinions of consumers enabling them to be influential at the development and implementation stages of any such initiatives.

The introduction of a PHNC nurse position to address cardiometabolic health may be one possible strategy to redress inequity in access to, and provision of, physical health care. The capacity of such a role to address consumer physic al health dispanties has been well received by nurses (Ha ppell et al. 2014a; Happell et al. 2014b), partic ula rly following the implementation of a similar role (Happell et al. 2015). Consumer input in the early stages of the design, structure and development of this position is crucial.

Partic ipants in the current study responded positively to the idea of a specialist nurse role, acknowledging the potential to enhance consumer access to physic al health care. The lack of integration between physic al and 
mental health servic es has been identified from qualita tive data collected from health professionals and mental health consumers (a lbeit limited) in other studies (Chad wick et al. 2012; Lester et al. 2005; Borba et al. 2012; Bradford et al. 2008; Brunero \& La mont 2010; Shuel et al. 2010; Brunero et a l. 2008). An embedded PHNC primary health nurse could provide a crucial conduit and thus bridge the gap between physical health and clinical mental health care provision, resulting in improved consumer outc omes for both sectors (Happell et al. 2012a). The research in this field is currently limited; however, there is evidence that specialist roles of this kind can improve the integration of mental and physic al health trea tment and monitoring (Druss et al. 2010; McKenna et al. 2014; Happell et al. 2014b; Brunero \& Lamont 2010) and ultima tely enhance quality health care.

Importantly, the current research findings reinforce the importance of breaking down existing professional silos and inc reasing collaboration within multidisciplinary mental health tea ms. Consumers interpreted siloing as a reticence of the mental health disciplines to collaborate across professional boundaries to provide optimal care and treatment. The tendency towards "tribalism" (Braithwaite 2010) and "professional homophily" (West \& Barron 2005), where each profession works in relative isolation from others, 
unfortuna tely presents a major ba mier to an integrated approach to care and trea tment. This tendency for professional silos (see also Bra ithwa ite 2006; Finn et al. 2010) would need to be acknowledged and addressed during implementation to avoid the new role becoming yet a nother health professional the consumer sees in isolation from the treating team as a whole. Previous resea rch highlights the benefits of multid isic iplinary collaboration on nursing care. Happell and colleagues (2013) showed substantial variability in how regularly nurses disc ussed physic al health issues of consumers with other professions. The frequency of collaborations correlated positively with the number of direct interventions with consumers (Bradford et al. 2008) demonstrating a relationship between collaboration and the provision of physic al health care and reinforcing the importance of the multidisc iplinary team a pproach.

\section{1}

The PHNC is proposed as an appropriate inclusion to the multidisciplinary team provid ing servic es for inpatient units and community health services (Ha ppell et al. 2012a). Partic ipants saw the notion of a dedic ated nursing position as having particular relevance for community mental health services. Community settings were seen to provide the scope to change the culture from a biomedical and clinic al focus to a greater 
emphasis on psycho-social issues, health promotion, emotional well-being and social inclusion. These outlooks are consistent with calls in the literature for a broaderand more holistic approach to health in the community (Ramon et al. 2007; Mezzina et al. 2006; Mann et al. 2004). The continuing dominance of biomedic al perspectives on health care was seen as a potential ba mier to the $\mathrm{CHN}$ performing non-c linic al functions, such as coordination and effective communic ation. These concems echo those from nurses about what is seen as the dominant influence of biomedical approaches to care on their practice (Ric hardson \& MacGibbon 2010; Cutc liffe et al. 2013).

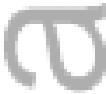

While integration and the need for a cultural shift were partic ula rly apparent, concems voiced by partic ipants highlighted the interrelated nature of these themes. Specific workplace culture may be a factor in the extent to which a lack of integration and a need for culture shift a re present. A professional setting where staff strongly a dhere to their identities and their professional group (indic ating rigid roles and a potential lack of cultural shift) is likely to be an obstacle to authentic collaboration and to result in lack of integration. The well documented collec tive stigma tised attitudes towards consumers reflect a major theme identified in the literature; the vast power 
imbalance between consumers and health professionals (Bennetts et al. 2011; Brunero et al. 2008; National Mental Health Commission 2014). The disempowement of consumers has a dversely impacted on the physic al health disc ussions, with the consumer voice not clearly artic ulated. The absence of a strong consumer voice to inform responses to the issues of integration and culture means these themes are likely to persist and pose a major bamier to improved physic al health care for mental health consumers.

$\infty$

Consumer representation on committees to implement the $\mathrm{PHCN}$ roles was raised as an essential component of new initia tives. Enhanced consumer participation is urgently required to fomulate consumer-centred solutions that improve access to physic al health services. The available knowledge on consumers' experiences of issues of physic al health service provision has been critic al to furthering the understanding of ba miers in the health care system. The consumer perspec tive is especially relevant when exploring the healthcare joumey; from first contact with services to ongoing continuity of care (Chadwick et al. 2012; Happell et al. 2012b).

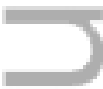

The inclusion of consumer perspective is growing in the mental health field, albeit much progress is still to be made (Bennetts et al. 2011). While 
there are some studies of consumer perspectives on access to physic al health care (Lester et al. 2005; O'Day et al. 2005), there is minimal research literature on consumer views on physic al health care reform within mental health settings. This study has contributed to addressing this knowledge gap. Existing practic es where mental health c linic ians refer consumers to extemal servic es for physic al health care has been largely ineffec tive.

The integration of physical and mental health care is therefore urgently needed to redress the current inequity (van Meijel et al. in press; Shuel et al. 2010; Mitchell et al. 2015). Consumers need to be the critic al reference group, central to all activities and active at all levels throughout the research agenda to ensure the issues identified and the corresponding strategies a re appropriate. This ideally would include consumer involvement in designing and directing the research, as recommended in the literature on consumerled research (Horsfall et al. 2007; van Draanen et al. 2013; Rose 2011). Transferable frameworks to enhance consumer participation, with consumers as co-researchers, will provide a suitable starting point (Ochocka et al. 2002; Hancock et al. 2012). The benefits of consumer researchers include producing different findings to those implemented by non-consumers (Clark et al. 1999). 
The inclusion of the consumer perspective in this study has resulted in an enhanced understanding of the issues of integration and professional culture. A dedic ated physical health care role has the potential to holistic ally integrate physical health care into the existing clinical care of mental health consumers. A trial of a specialist physic al health nurse role in a community mental health service demonstrated effectiveness in terms of linking mental health consumers to a variety of servic es such as allied health and primary care (Brunero \& Lamont 2010). The nurse initiated referrals for 62 per cent of the mental health consumers to primary care, allied health or communitybased seryic es and for routine blood testing, mammography sc reening and nutrition counselling, with high follow up rates (Brunero \& La mont 2010). Previous studies have also shown such a role is well-supported by nurses in mental health (Happell et al. 2014a; Happell et al. 2012a). These research findings add the weight of consumer support. There is a sense from consumers that organisation and struc ture are important to the success of the PCNC role.

The unique demands on the PHNC will require the incumbent to have a strong interpersonal skill set and the capacity to advocate for consumers. It is likely that the role will need a person with a strong background in both 
physic al health nursing and mental health. This would facilita te clinic al credibility by the health sector generally by mental health consumers, inc lud ing equitable physic al health care provision and access to services. It would be incumbent of the $\mathrm{CHN}$ to also play a role in community and clinical education to improve inter-professional collaboration and understanding to maximise utilisation of the role, and the subsequent benefits for consumers.

\section{Limitations}

Mental health consumers, including those who participate in research, are very diverse people. Others consumers may have views that differ from those of the partic ipants in the current study. Further research with the active involvement of mental health consumers is needed and will be valua ble to determine the effic acy of PHNC type roles and how their effectiveness can be maximised.

\section{Conclusions}

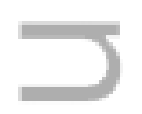

A PHNC position has the potential to improve access to physical health care in mental health settings and is likely to be considered favourably by 
consumers. The development of this role must occur with ongoing consumer input and consideration of cultural and structural changes to the public health care system. The dearth of consumer perspective in the vast majority of physical health research is problematic and needs to be addressed as a human rights issue. High level involvement of mental health consumers to further enhance understanding of the existing bariers to equitable care and developing and evaluating strategies in this a rea a re vital. Reducing inequities in physic al hea lth status of mental health consumers is slowly being considered in health care system reform. Consumer leadership and participation must be a central feature in the reform to physic al health care services.

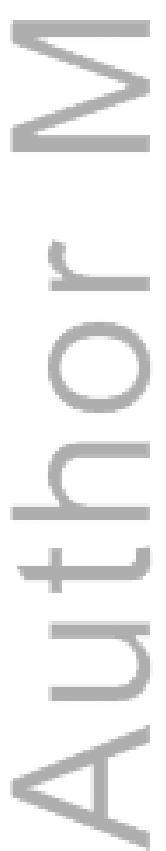




\section{References}

Bennetts, W., Cross, W. \& Bloomer, M. (2011). Understanding consumer partic ipation in mental health: Issues of power and change. Intemational J oumal of Mental Health Nursing, 20, 155-164.

Borba, C.P., DePadilla, L., McCarty, F. A., von Esenwein, S. A., Druss, B. G. \& Sterk, C. E. (2012). A qualita tive study examining the perceived bariers and facilita tors to medic al healthca re servic es among women with a serious mental illness. Womens Health Issues, 22, e217-224.

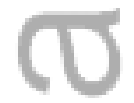

Bradford, D. W., Kim, M. M., Braxton, L. E., Marx, C. E., Butterfield, M. \& Elbogen, E. B. (2008). Access to medic al care among persons with psychotic and major affective disorders. Psychiatr Serv, 59, 847-852.

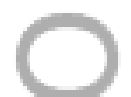

Braithwaite, J . (2006). An empiric al assessment of social structural and cultural change in clinic al direc torates. Health Care Analysis, 14, 185-193. 
Braithwaite, J . (2010). Between-group behaviour in health care: gaps, edges, boundaries, disconnections, weak ties, spaces and holes. A systematic review. BMC Health Services Research, 10, 330.

Braun, V. \& Clarke, V. (2006). Using thematic a nalysis in psychology. Qua litative Research in Psychology, 3, 77-101.

Brunero, S. \& Lamont, S. (2009). Systematic sc reening for meta bolic syndrome in consumers with severe mental illness. Intemational J oumal of Mental Health Nursing, 18, 144-150.

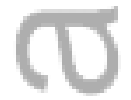

Brunero, S. \& Lamont, S. (2010). Hea lth behaviour beliefs and physic al health risk factors for c a rd iova sc ular disea se in an outpatient sa mple of consumers with a severe mental illness: A cross-sectional survey. Intemational I oumal of Nursing Studies, 47, 753-760.

Brunero, S., La mont, S., Myrtle, L \& Fa irbrother, G. (2008). The Blue Card: a hand-held health record card for mental health consumers with comorbid physic al health risk. Australasian Psychiatry, 16, 238-243. 
Chadwick, A., Street, C., McAndrew, S. \& Deacon, M. (2012). Minding our own bodies: Reviewing the literature regarding the perceptions of service users diagnosed with serious mental illness on ba miers to accessing physic al health care. Intemational J oumal of Mental Health Nursing, 21, 211-219.

Clark, C. C., Sc ott, E. A., Boydell, K. M. \& Goening, P. (1999). Effects of client intenviewers on client-reported satisfaction with mental health servic es. Psychiatric Servic es, 50, 961-963.

Commonwealth of Australia (2013). A national framework for recoveryoriented mental health servic es: policy and theory. Canberra Australian Health Ministers' Advisory Council.

Cutc liffe, J., Stevenson, C. \& La keman, R. (2013). Oxymoronic or synergistic: deconstructing the psychiatric and/or mental health nurse. Int J Ment Health Nurs, 22, 125-134.

Druss, B. G., von Esenwein, S. A., Compton, M. T., Rask, K. J ., Zhao, L. \& Parker, R. M. (2010). A randomized trial of medical care management for community mental health settings: the Primary Care Access, Referral, 
and Evaluation (PCARE) study. Americ an J oumal of Psychia try, 167, 151-159.

Finn, R, Leamonth, M. \& Reedy, P. (2010). Some unintended effects of tea mwork in healthcare. Social Science and Medicine, 70, 1148-1154. s.

Hancock, N., Bundy, A., Tamsett, S. \& McMahon, M. (2012). Partic ipation of mental health consumers in research: Tra ining addressed and reliability assessed. Australian Occupation Therapy J oumal, 59, 218-224.

Happell, B., Platania-Phung, C., Sc ott, D. \& Stanton, R. (2014a). Predic tors of nurse support for the introduction of the card iometabolic health nurse in the australian mental health sector. Perspectives in Psychiatric Care, DOI: 10.1111/ppc.12077.

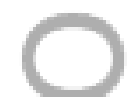

Happell, B., Sc ott, D. \& Platania-Phung, C. (2012a). Nurse views on the cardiometabolic health nurse as an approach to improving the physic al health of people with serious mental illness in australia. Intemational J oumal of Mental Hea Ith Nursing, d oi: 10.1111/j.14470349.2012.00892.x. 
Happell, B., Sc ott, D. \& Platania Phung, C. (2012b). Perceptions of ba miers to physic al health care for people with serious mental illness: A review of the intemational litera ture. Issues in Mental Health Nursing, 33, 752-761.

Happell, B., Stanton, R., Hoey, W. \& Sc ott, D. (2014b). Cardiometa bolic Health Nursing to Improve Health and Primary Care Access in Community Mental Health Consumers: Ba seline Physic al Health Outc omes from a Randomised Controlled Trial. Issues in Mental Health Nursing, 35, 114121.

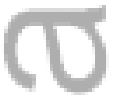

Happell, B., Stanton, R., Hoey, W. \& Sc ott, D. (2015). Reduced Ambivalence to the Role of the Cardiometabolic Health Nurse Following a 6-Month Trial. Perspectives in Psychiatric Care, 51, 80-85.

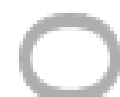

Horsfall, J., Cleary, M., Wa Iter, G. \& Malins, G. (2007). Challenging conventional practice: placing consumers at the centre of the resea rch enterprise. Issues Mental Health Nursing, 28, 1201-1213. 
Hyland, B., J udd, F., Davidson, S., J olley, D. \& Hocking, B. (2003). Case managers' attitudes to the physic al health of their patients. Australian and New Zealand J oumal of Psychiatry, 37, 710-714.

Kaufman, E. A., McDonell, M. G., Cristofa lo, M. A. \& Ries, R. K. (2012). Exploring Ba miers to Primary Care For Patients with Severe Mental Illness: Frontline Patient and Provider Accounts. Issues in Mental Hea Ith Nursing, 33, 172180.

Lambert, T. J . \& Newcomer, J . M. (2009). Are the cardiometa bolic complic a tions of sc hizo prehnia still neglected? Bamiers to care. Medic al J oumal of Australia, 190, S39-42.

Lawrence, D., Hancock, K. J. \& Kisely, S. (2013). The gap in life expectancy from preventa ble physic al illness in psychia tric patients in Westem Australia: Retrospec tive analysis of population ba sed registers. British Medic al J oumal, 346, 2539.

Lawrence, D. \& Kisely, S. (2010). Inequa lities in healthc a re provision for people with severe mental illness. J oumal of Psychopha macology, 24, 61-68. 
Lester, H., Tritter, J . Q . \& Sorohan, H. (2005). Patients' and health professionals' views on primary care for people with serious mental illness: focus group study. British Medic al J oumal, 330, 1122.

Lorig, K., Ritter, P. L., Pifer, C. \& Wemer, P. (2014). Effectiveness of the chronic disease self-management program for persons with a serious mental illness: A translation study. Community Mental Health J oumal, 50, 96103.

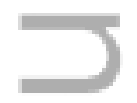

Mann, M., Hosman, C. M., Schaalma, H. P. \& de Vries, N. K. (2004). Selfesteem in a broad-spectrum approach for mental health promotion. Health Educ Res, 19, 357-372.

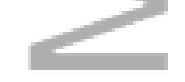

McKenna, B., Fumess, T., Wa llace, E., et al. (2014). The effec tiveness of specialist roles in mental health metabolic monitoning: a retrospective cross-sectional comparison study. BMC Psychiatry, 14, 234.

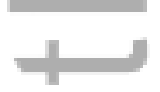

Mezzina, R., Davidson, L., Borg, M., Marin, I., Topor, A. \& Sells, D. (2006). The social nature of recovery: disc ussion and implic ations for practice. American J oumal of Psychiatric Rehabilitation, 9, 63-80. 
Millar, F., Sands, N. \& Elsom, S. (2014). Factors influencing cardiometa bolic monitoring practic es in an adult community mental health service. Intemational J oumal of Mental Hea Ith Nursing, 23, 479-489.

Mitc hell, A. J ., Vancampfort, D., De Hert, M. \& Stubbs, B. (2015). Do people with mental illness receive adequate smoking cessation advice? A systematic review and meta-analysis. General Hospital Psychia try, 37, 14-23.

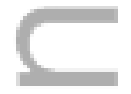

Nankivell, J ., Platania-Phung, C., Happell, B. \& Scott, D. (2013). Access to physic al health care for people with serious mental illness: a nursing perspective and a human rights perspective - common ground? Issues in Mental Health Nursing, 34, 442-450.

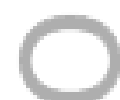

National Mental Health Commission (2014). The National Review of Mental Health Programmes and Services. . Sydney. 
O'Day, B., Killeen, M. B., Sutton, J . \& lezzoni, L. I. (2005). Primary care experiences of people with psychiatric disabilities: bamiers to care and potential solutions. Psyc hia tr Reha bil J , 28, 339-345.

Ochocka, J., Janzen, R. \& Nelson, G. (2002). Shaning power and knowledge: professional and mental health consumer/survivor researchers working together in a partic ipatory action research project. Psychiatr Rehabil J, 25, 379-387.

Ramon, S., Healy, B. \& Renouf, N. (2007). Recovery from mental illness as an emergent concept and practice in Australia and the UK. Intemational Joumal of Social Psychiatry, 53, 108-122.

Richardson, F. \& MacGibbon, L. (2010). Cultural sa fety: Nurses' ac counts of negotiating the order of things. Women's Studies J oumal, 24, 54-65.

Robson, D, \& Gray, R. (2007). Serious mental illness and physic al health problems: a discussion paper. Intemational J oumal of Nursing Studies, 44, 457-466. 
Robson, D., Haddad, M., Gray, R. \& Goumay, K. (2013). Mental health nursing and physic al health care: a cross-sec tional study of nurses' attitudes, practice, and perceived training needs for the physical health care of people with severe mental illness. Intemational J oumal of Mental Health Nursing, 22, 409-417.

Rose, D. (2011). Service user views and service user research in the J oumal of Mental Health. J oumal of Mental Health, 20, 423-428.

Schmutte, T., Flana gan, E., Bedregal, L, et al. (2009). Self-Effic acy and SelfCare: Missing Ingredients in Health and Healthcare a mong Adults with Serious Mental Illnesses. Psyc hiatric Q uarterly, 80, 1.

Shuel, F., White, J ., J ones, M. \& Gray, R. (2010). Using the serious mental illness health improvement profile [HIP] to identify physical problems in a cohort of community patients: a pragmatic case series evaluation. Intemational J oumal of Nursing Studies, 47, 136-145. 
Stanley, S. H. \& Laughame, J. D. E. (2014). The impact of lifestyle factors on the physic al health of people with a mental illness: A brief review. Intemational J oumal of Behavioral Medic ine, 22, 275-281.

Stebbens, R. (2001). Exploratory research in the social sciences: Qualitative research methods: Volume 48, London: Sage Public ations.

van Draanen, J., J eyaratnam, J ., O'Campo, P., et al. (2013). Meaningful inclusion of consumers in research and service delivery. Psychiatr Rehabil J , 36, 180-186.

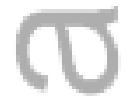

van Meijel, B., van Hamerserveld, S., van Gool, R., van der Bijl, J . \& van Harten, P. (in press). Effects and fea sibility of the "traffic light method for somatic sc reening and lifestyle" in patients with severe mental illness: a pilot study. Perspectives in Psychiatric Care.

West, E. \& Barron, D. N. (2005). Social and geogra phic al bounda ries a round senior nurse and physician leaders: an a pplic ation of social network analysis. Canadian J oumal of Nursing Research, 37, 132-148. 
Wheeler, A. J ., Ha mison, J ., Mohini, P., Nardan, J ., Tsai, A. \& Tsai, E. (2010).

Cardiovascular risk assessment and management in mental health

clients: whose role is it anyway? Community Mental Health J oumal, 46, 531-539.

1.

(

$\int$

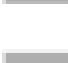

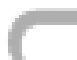

ד

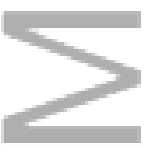

(

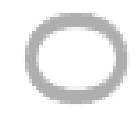

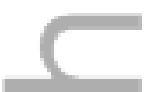

$+$

(

1

This article is protected by copyright. All rights reserved. 
Embedding a physical health nurse consultant within mental health services: consumers perspectives

\section{Authors:}

Professor Brenda Happell*

RN, RPN, BA (Hons), Dip Ed, B Ed, M Ed, PhD

Professor of Nursing, and Executive Director,

Synergy, Nursing and Midwifery Research Centre

University of Ca nberra, Fa culty of Health, and

\section{ACTHealth}

Build ing 6, Level 3

Canberra Hospital

PO BOX 11 WODEN 2606

Australia

Email brenda.happell@canberra.edu.au

Phone: 61262442333

Ms Stephanie Ewart

Research Assistant

Synergy, Nursing and Midwifery Research Centre

University of Canberra and ACTHealth

B.Bus, Graduate Diploma in Vocational and Workplace Leaming 
Independent Consumer Academic

Life Expectancy Advocate (Mental Health)

DrChris Platania-Phung

BA (Hons), PhD

Research Fellow

Synergy, Nursing and Midwifery Research Centre

University of Canberra, Faculty of Health, and

ACTHealth

Building 6, Level 3

Canberra Hospital

PO BOX 11 WODEN 2606

Australia

0401008447

Ms J ulia Bocking

PhD Candidate

Research Officer

Synergy, Nursing and Midwifery Research Centre

University of Canberra, Faculty of Health, and

ACTHealth

Professor Kathleen G riffiths

$\mathrm{PhD}$ 
Professor \& Director,

National Institute for Mental Health Research,

Research School of Population Health,

Australian Nationa I University

Acton. ACT. 2601.

Ph. +61261259723.

Fax. +61261250733

Dr Brett Scholz

BHSc i (Hons), PhD

Research Fellow

Synergy, Nursing and Midwifery Research Centre

University of Ca nberra, Fa culty of Health, and

ACTHealth

Building 6, Level 3

Canberra Hospita I

PO Box 11 WODEN 2606

Australia

Brett.Scholz@canberra.edu.au

MrRobert Stanton

BHMSC (Hons) ESSAM AEP

Lecturer

Central Queensland University, 
School of Medical and Applied Sciences

Bruce Highway, Rockhampton, 4702

Queensland

Australia

r.stanton@cqu.edu.au,

(07) 49232275

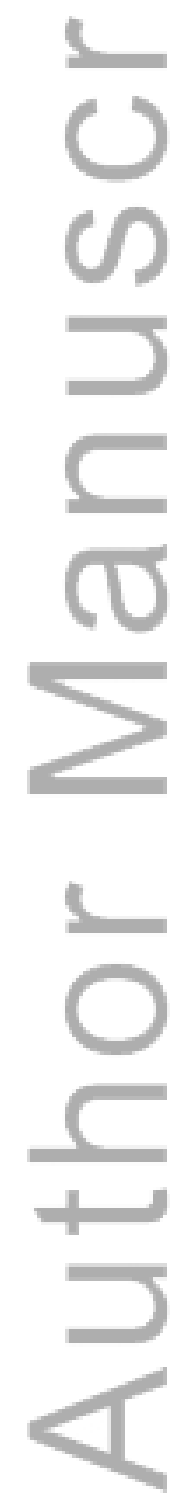

This article is protected by copyright. All rights reserved. 


\section{ACKNOWFDGEMENTS}

The research team extend our sincere thanks to the ACTMental Health

Consumer Network for fac ilita ting this research through access to

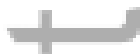

participants, organising the focus groups, providing the venue and fantastic catering and for being generally wonderful.

Thanks so much to the partic ipants for your generosity and openness in sha ring your views.

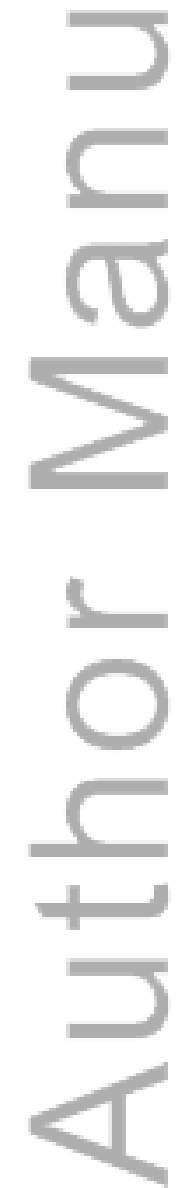




\section{University Library}

\section{- M M N E R VA A gateway to Melbourne's research publications}

Minerva Access is the Institutional Repository of The University of Melbourne

\section{Author/s:}

Happell, B;Ewart, SB;Platania-Phung, C;Bocking, J;Griffiths, K;Scholz, B;Stanton, R

Title:

Embedding a physical health nurse consultant within mental health services: Consumers' perspectives.

\section{Date:}

2016-08

\section{Citation:}

Happell, B., Ewart, S. B., Platania-Phung, C., Bocking, J., Griffiths, K., Scholz, B. \& Stanton, R. (2016). Embedding a physical health nurse consultant within mental health services: Consumers' perspectives.. Int J Ment Health Nurs, 25 (4), pp.377-384. https:// doi.org/10.1111/inm.12185.

Persistent Link:

http://hdl.handle.net/11343/290801 